John A. Main, Steven W. Peterson, and Alvin M. Strauss 
The appearance of the ISSN code at the bottom of this page indicates SAE's consent that copies of the paper may be made for personal or internal use of specilic clients. This consent is given on the condition, however, that the copier pay a \$5.00 per article copy fee through the Copyright Clearance Center, Inc. Operations Center, 27 Congress St. Salem, MA 01970 for copying beyond that permitted by Sections 107 or 108 of the U.S. Copyright Law. This consent does not extend to other kinds of copying such as copying for general distribution, for advertising or promotional purposes, for creating new collective works, or for resale.

SAE routinely stocks printed papers for a period of three years following date of publication. Direct your orders to SAE Customer Service Department.

To obtain quantity reprint rates, permission to reprint a technical paper or permission to use copyrighted SAE publications in other works, contact the SAE Publications Group.

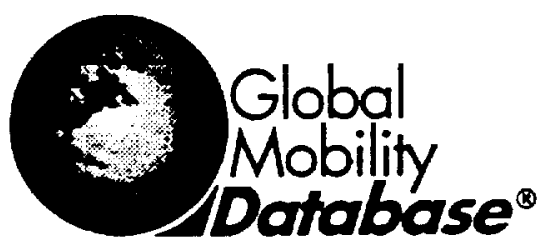

All SAE papers, standards, and selected books are abstracted and indexed in the SAE Global Mobility Database.

No part of this publication may by reproduced in any form, in an electronic retrieval system or otherwise, without the prior written permission of the publisher.

\section{ISSN 0148-7191 \\ Copyright 1992 Society of Automotive Engineers, Inc.}

Positions and opinions advanced in this paper are those of the author(s) and not necessarily those of SAE. The author is solely responsible for the content of the paper. A process is available by which discussions will be printed with the paper if it is published in SAE transactions. For permission to publish this paper in full or in part, contact the SAE Publications Division.

Persons wishing to submit papers to be considered for presentation or publication through SAE should send the manuscript or a 300 word abstract of a proposed manuscript to: Secretary, Engineering Activity Board, SAE.

\section{Printed in USA}




\title{
Power Assist EVA Glove Development
}

\author{
John A. Main, Steven W. Peterson, and Alvin M. Strauss
}

Vanderbilt Univ.

ABSTRACT

Structural modelling of the EVA glove indicates that flexibility in the metacarpophalangeal (MCP) joint can be improved by selectively lowering the elasticity of the glove fabric. Two strategies are used to accomplish this. One method uses coil springs on the back of the glove to carry the tension in the glove skin due to pressurization. These springs carry the loads normally borne by the glove fabric, but are more easily deformed. An active system was also designed for the same purpose and uses gas filled bladders attached to the back of the EVA glove that change the dimensions of the back of the glove and allow the glove to bend at the MCP joint, thus providing greater flexibility at this joint. A threshold control scheme was devised to control the action of the joint actuators. Input to the controller was provided by thin resistive pressure sensors placed between the hand and the pressurized glove.

The pressure sensors consist of a layer of polyester film that has a thin layer of ink screened on the surface. The resistivity of the ink is pressure dependent, so an extremely thin pressure sensor can be fabricated by covering the ink patch with another layer of polyester film and measuring the changing resistance of the ink with a bridge circuit. In order to sense the force between the hand and the glove at the MCP joint a sensor was placed on the palmar face of the middle finger. The resultant signal was used by the controller to decide whether to fill or exhaust the bladder actuators on the back of the glove. The information from the sensor can also be used to evaluate the effectiveness of a given control scheme or glove design since the magnitude of the measured pressures gives some idea of the torque required to bend a glove finger at the MCP joint.

Tests of this actuator, sensor, and control system were conducted in an $57.2 \mathrm{kPa}$ glove box by performing a series of 90 degree finger bends with a glove without an MCP joint assembly, a glove with the coil spring assembly, and with the four fingered actuated glove. The tests of these three glove designs confirm the validity of the model.

\section{INTRODUCTION}

One of the primary difficulties in designing a more flexible metacarpophalangeal (MCP) joint for the EVA glove is the geometry of the hand and the complexity of the surrounding fabric structure, i. e. the glove itself. Fabric structures do not lend themselves easily to structural modelling in the conventional sense: while fabric is approximately linearly elastic in tension it wrinkles in response to compressive loads. With some simplification, however, a workable structural model of the MCP joint can be devised.

Examination of a pressurized fabric glove indicates that the region surrounding the hand at the MCP joint is analogous to a pressurized tube. Although dependant upon the geometry of the palm bar and the tightness of fit, the cross-section of the glove at this point can be approximated by an ellipse. For the purposes of this discussion the EVA glove at the MCP joint can, without loss of generality, be simplified further by representing it by a pressurized fabric tube with a circular cross section.

\section{NOMENCLATURE}

$\begin{array}{ll}\mathrm{P} & \text { beam inflation pressure }(\mathrm{Pa}) \\ \mathrm{I} & \text { radius of inflated beam }(\mathrm{m}) \\ \mathrm{X} & \text { axial beam coordinate }(\mathrm{m}) \\ \mathrm{E} & \text { beam fabric modulus }(\mathrm{N} / \mathrm{m}) \\ \mathrm{I} & \text { inflated beam moment of inertia }\left(\mathrm{m}^{3}\right) \\ \mathrm{M} & \text { applied bending moment }(\mathrm{N}-\mathrm{m}) \\ \mathrm{N} & \text { axial stress resultant }(\mathrm{N} / \mathrm{m}) \\ P & \text { radius of curvature }(\mathrm{m}) \\ \theta & \text { angular position (radians) }\end{array}$

\section{ANALYSIS OF THE EVA GLOVE MCP JOINT}

Comer and Levy (1963) modelled bending of cylindrical membrane structures in a manner analogous to conventional beam theory. The following structural analysis closely follows the method used by Comer and Levy with some modifications to make the results more 


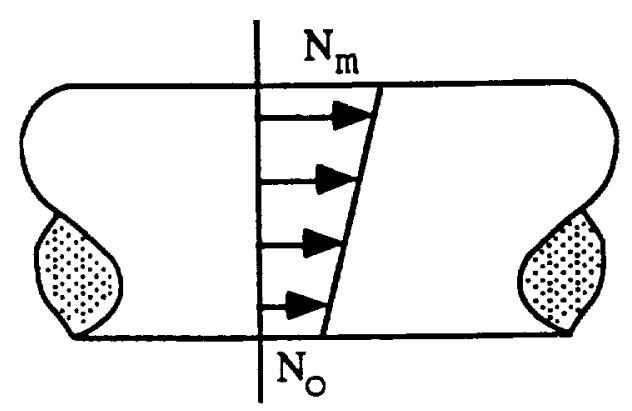

Figure 1. The stress distribution in the fabric of the glove MCP joint in regions where no wrinkling is present.

applicable to fabric structures. These changes include the use of stress resultants instead of stress and the expression of the fabric modulus in terms of force per unit width.

Figure 1 shows a sketch of an idealized EVA glove MCP joint. It is a simple cylindrical fabric structure supported by internal pressure. An arbitrary loading of the joint can be expressed by applied moments that are functions of the axial coordinate $x$. A model of an inflated structure must accommodate both slack and taut regions in the fabric. In the taut regions, where the axial stress in a given cross-section of the fabric of the glove remains tensile around the complete circumference, the stress distribution illustrated in Figure 1 is assumed.

In these regions the value of the axial stress resultant in the glove fabric is defined as

$$
N=N_{0}\left(\frac{1+008 \theta}{2}\right)+N_{2}\left(\frac{1-008 \theta}{2}\right)
$$

In this expression $\theta$ is measured around the circumference of the beam from the point where $\mathrm{N}=$ $N_{0}$. (i.e. if the glove is loaded in flexion, $N=N_{0}$ on the palmar side of the glove)

When the applied moment from the hand exceeds the value $\pi r^{3} p / 2$ the bending stress just cancels the axial stress in the fabric skin on the palmar side of the glove and wrinkling will begin in that region. The fabric wrinkles because it is incapable of resisting compressive loads. In these regions the stress distribution illustrated in Figure $\mathbf{2}$ is assumed. In these regions the stress resultant in the axial direction in the fabric skin is

$$
\begin{array}{ll}
N=\left(\frac{\cos \theta_{0}-\cos \theta}{1+\cos \theta_{0}}\right) N_{m} & \pi>\theta>\theta_{0} \\
N=0 & \theta_{0}>\theta>0
\end{array}
$$

For the balance of moments about a transverse axis through the center of the glove

$$
M(x)=-2 \int_{0}^{\pi} N x^{2} 000 \theta d \theta
$$

When $M>\pi r^{3} p / 2$ equations 2 and 3 can be combined to give

$$
N_{m}=\frac{2 X(x)\left(1+000 \theta_{0}\right)}{r^{2}\left(2 \pi-2 \theta_{0}+0102 \theta_{0}\right)}
$$

For a balance of axial forces on any given cross section

$$
p \pi r^{2}-2 \int_{\delta}^{\pi} N=d \theta
$$

Again considering the regions containing wrinkled fabric, equations 2 and 5 can be combined to give

$$
p \pi x^{2}-2 \int_{0}^{x} N=d \theta
$$

Equating the expressions for $\mathrm{N}_{\mathrm{m}}$ in equations 4 and 6 yields

$$
\frac{M(x)}{\mathrm{pr}^{3}}=\frac{\pi\left(2 \pi-2 \theta_{0}+\sin 2 \theta_{0}\right)}{4\left(\left(\pi-\theta_{0}\right) 00 \cos \theta_{0}+\sin \theta_{0}\right)}
$$




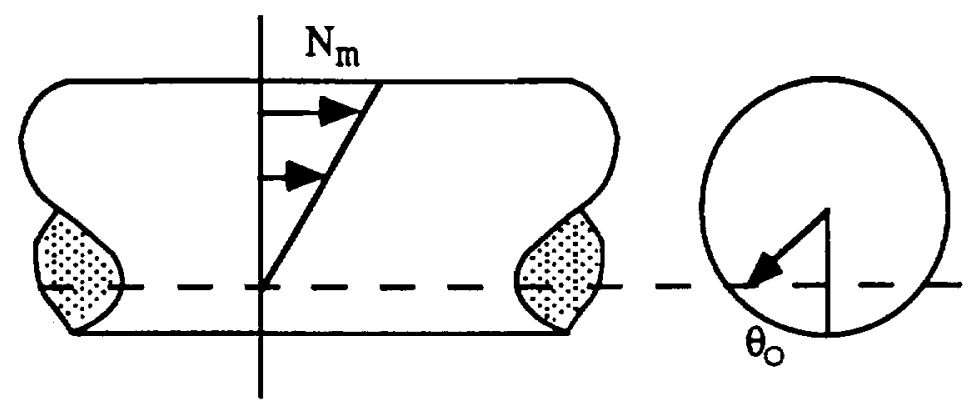

Figure 2. The stress distribution in the fabric of the EVA glove in regions where wrinkling occurs.

Considering now the regions where no wrinkling of the cross section occurs, substitution of equation 1 into equation 3 gives

$$
N_{m}-N_{0}=2 x(x) / \pi x^{2}
$$

Substituting equation 1 into equation 5 yields

$$
N_{m}+N_{0}-p r
$$

Combining equations 8 and 9 yields

$$
\therefore \mathrm{N}_{m}-\left(M(x) / \pi r^{2}\right)+(\operatorname{pr} / 2)
$$
is given by

The curvature of the glove joint that is wrinkled

$$
\frac{1}{p}=\frac{\left(N_{m} / \Sigma\right)}{x\left(1+\cos \theta_{0}\right)}
$$

Substituting in the expression for $\mathrm{N}_{\mathrm{m}}$ in equation 4 yields

$$
\frac{1}{p}=\frac{2 Y(x)}{E I^{3}\left(2 \pi-2 \theta_{0}+\sin 2 \theta_{0}\right)}
$$

The curvature of the joint when no wrinkling is present is given by

$$
\frac{1}{\rho}=\frac{\left(N_{m}-N_{0}\right)}{2 E I}
$$

Substituting equation 8 into equation 13 yields

$$
\frac{1}{p}=\frac{M(x)}{\pi r^{3} E}
$$

Equations 12 and 14 can be combined so that the model of the simplified glove MCP joint subject to a bending moment can be expressed in the following form:

$$
\begin{aligned}
\frac{1}{\rho}-\frac{M(x)}{E I} & \\
I=\Sigma^{3}\left(\pi-\theta_{0}+\left(\sin 2 \theta_{0}\right) / 2\right) & \text { for } Y>\pi p^{3} / 2 \\
I-\pi r^{3} & \text { for } Y<\pi p r^{3} / 2
\end{aligned}
$$

When wrinkling occurs at the joint $\left(M>\pi r^{3} p / 2\right)$ equation 7 must be used to determine the angle $\theta_{\circ}$ that corresponds to the applied moment. Different geometries that might be more representative of the actual EVA glove can also be accommodated in this model simply by substituting the appropriate moment of inertia for the MCP joint cross-section. 


\section{GLOVE DESIGN}

In terms of the model embodied in equation 15. the goal of the EVA glove designer is to achieve a given joint curvature $(1 / p)$ while minimizing the necessary moment $(M)$ that must be supplied by the hand. One way to accomplish this (Main et al., 1991) is to supply a moment from exterior actuators to reduce the contribution necessary from the hand. The model also supports current efforts (Kosmo et al., 1988; Spampinato et al., 1990) to design and construct closer fitting gloves since, for a given glove curvature, the required applied moment from the hand can be reduced by lowering the moment of inertia (I) of the glove cross section. The lowest moment of inertia would be the closest fitting glove possible.

Examination of equation 15 leads to another technique for reducing the applied moment necessary to bend the MCP joint. This is accomplished by reducing the elasticity $(E)$, or spring constant, of the glove itself. One of the advantages of increasing joint mobility in this fashion is that, since the modifications are made only to the part of the glove that is in tension, the only hardware additions necessary are on the back of the hand. This means that hand/tool coupling is not compromised by the addition of hardware to the palm. The goal of this investigation was to reduce MCP stiffness in this fashion and verify the validity of the model in the process.

A unique glove was designed and constructed specifically for testing this concept. As shown in
Figures 3 and 4 , the test glove consists of a fabric restraint layer over a latex inner glove. The glove includes a palm bar to prevent ballooning, a strap over the back of the hand to further tighten the glove over the palm, and tucked fabric finger joints for finger mobility. An important feature of this glove is the inclusion of a large pleat that extends from the edges of the palm over the knuckles on the back of the hand. The effect of this pleat is to give the glove a pressurized neutral position with the fingers flexed approximately 60 degrees at the MCP joint.

The glove was designed to accept three distinct dorsal assemblies which change the characteristics of the MCP joint. These assemblies were mounted on the glove at attachment points at the base of each finger and a large velcro mount on the glove wrist. Each assembly has the effect of changing the neutral position of the glove fingers to a zero flexion angle. The simplest of the three dorsal assemblies is a panel of fabric that attaches to the wrist and is laced into the finger attachment points. This version (see Figure 5) is considered the standard version and is intended to be analogous to a pressurized glove without any MCP joint modifications. A coil spring dorsal assembly was also constructed (see Figure 6) and represents an attempt to increase MCP joint flexibility by lowering the spring constant of the load bearing structure on the back of the glove. The springs chosen for this assembly (SPEC Model E0360-039-2000, $k=0.508 \mathrm{~N} / \mathrm{mm}$, free length $=50.8 \mathrm{~mm}$, diameter $=9.14 \mathrm{~mm}$ ) have a spring

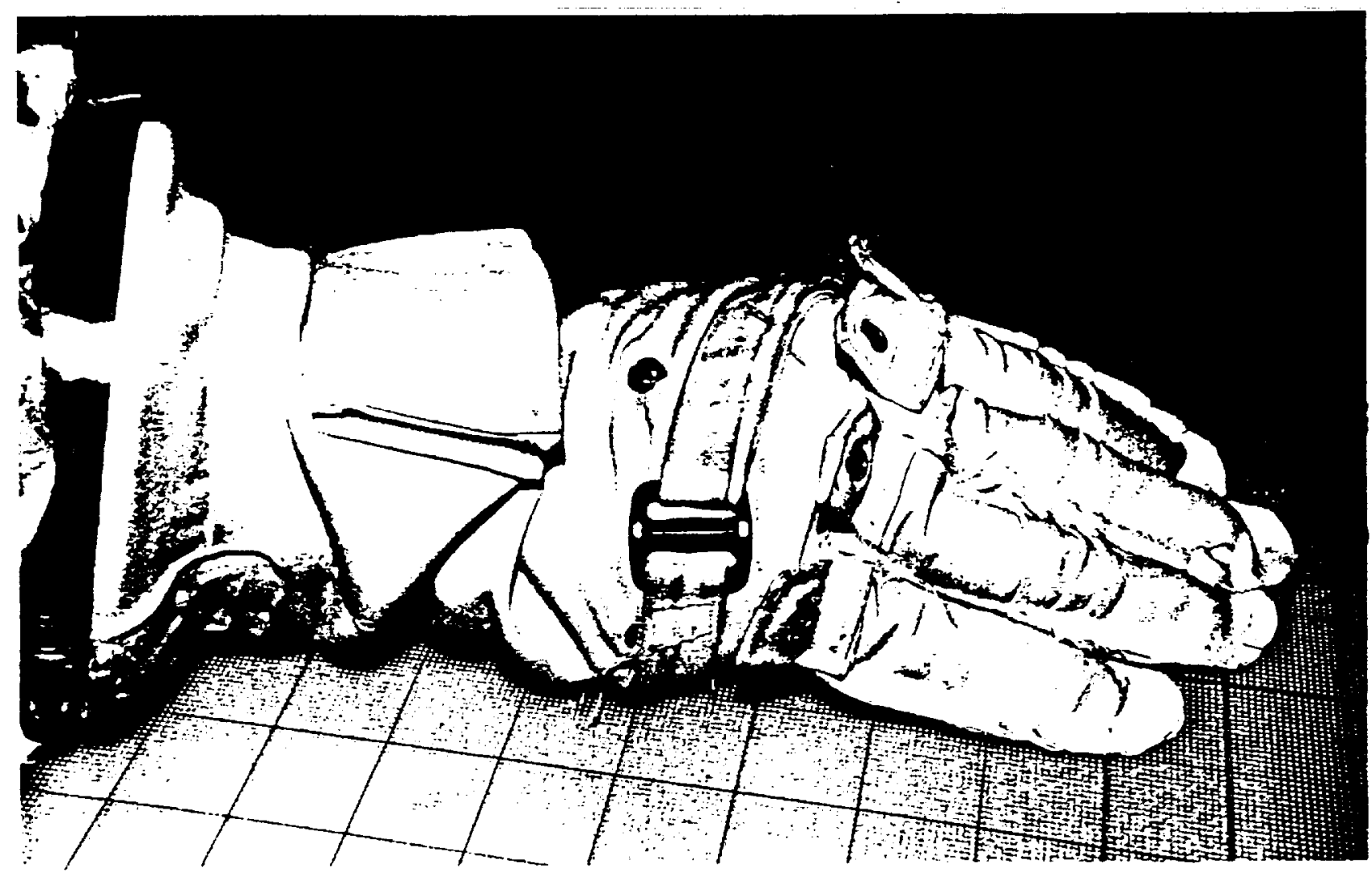

Figure 3. Photo of test glove without a dorsal assembly. 
constant significantly less than the fabric panel in the standard version.

A pneumatic actuator assembly was also constructed (see Figure 7) and was intended to further reduce the spring constant of the dorsal assembly by inclusion of an active subsystem. The design of the actuator is shown in Figure 8 . The neoprene tubes enclosed in the nylon sleeves have a spring constant that is approximately the same as the coil springs in the previously described dorsal assembly. There is, however, the added capability of extending the actuator by pressurizing it. The nylon sleeves are cut very long and thin (maximum diameter $15 \mathrm{~mm}$ ) so that, upon pressurization, the bladder will stretch and the actuator will lengthen, allowing the glove MCP joint to flex. The actuator is controlled using glove/finger contact pressure measurements obtained from a thin pressure sensor (Tekscan Button Sensor, see Figure 9) placed between the hand and the glove at the base of the middle finger of the right hand. The Tekscan sensor consists of a layer of polyester film that has a thin layer of ink screened on the surface. The resistivity of the ink is pressure dependent, so an extremely thin pressure sensor can be fabricated by covering the ink patch with another layer of polyester film and measuring the resistance change of the sensor with a bridge circuit. The stock Tekscan sensor has a thickness of $0.15 \mathrm{~mm}$. After lead attachment and application of a protective layer of insulating tape the sensor assembly has a thickness of $0.51 \mathrm{~mm}$.

The control strategy for the active system is illustrated in Figure 10. As the hand moves against the glove no action is taken by the control system until an upper pressure threshold $\left(V_{p}\right)$ is exceeded. At that point the pressurization valve opens and the actuator fills, allowing the finger to flex. The actuator extends to the point that the pressure between the hand and glove is reduced below the threshold $V_{p}$, closing the pressurization valve. When the hand extends back toward neutral position the pressure sensor reading will drop further and go below the lower threshold $\left(\mathrm{V}_{\mathrm{e}}\right)$. In this region the controller opens the exhaust valve.

The schematic of the controller circuit is included as Figure 11. The circuit consists of a bridge circuit for pressure measurement and an operational amplifier (NTE 857) to isolate the bridge as well as to amplify the signal. The function of the remainder of the circuit is summarized in Table 1 . The two 311 voltage comparators are set to switch from a HIGH state to LOW when the signal from the finger pressure sensor exceeds their preset thresholds, $V_{p}$ and $V_{e}$. The output of the comparators is connected to a pair of logic gates that control the action of the pressurization and exhaust valves. The NOR gate controls the action of the pressurization valve and the AND gate the exhaust valve.

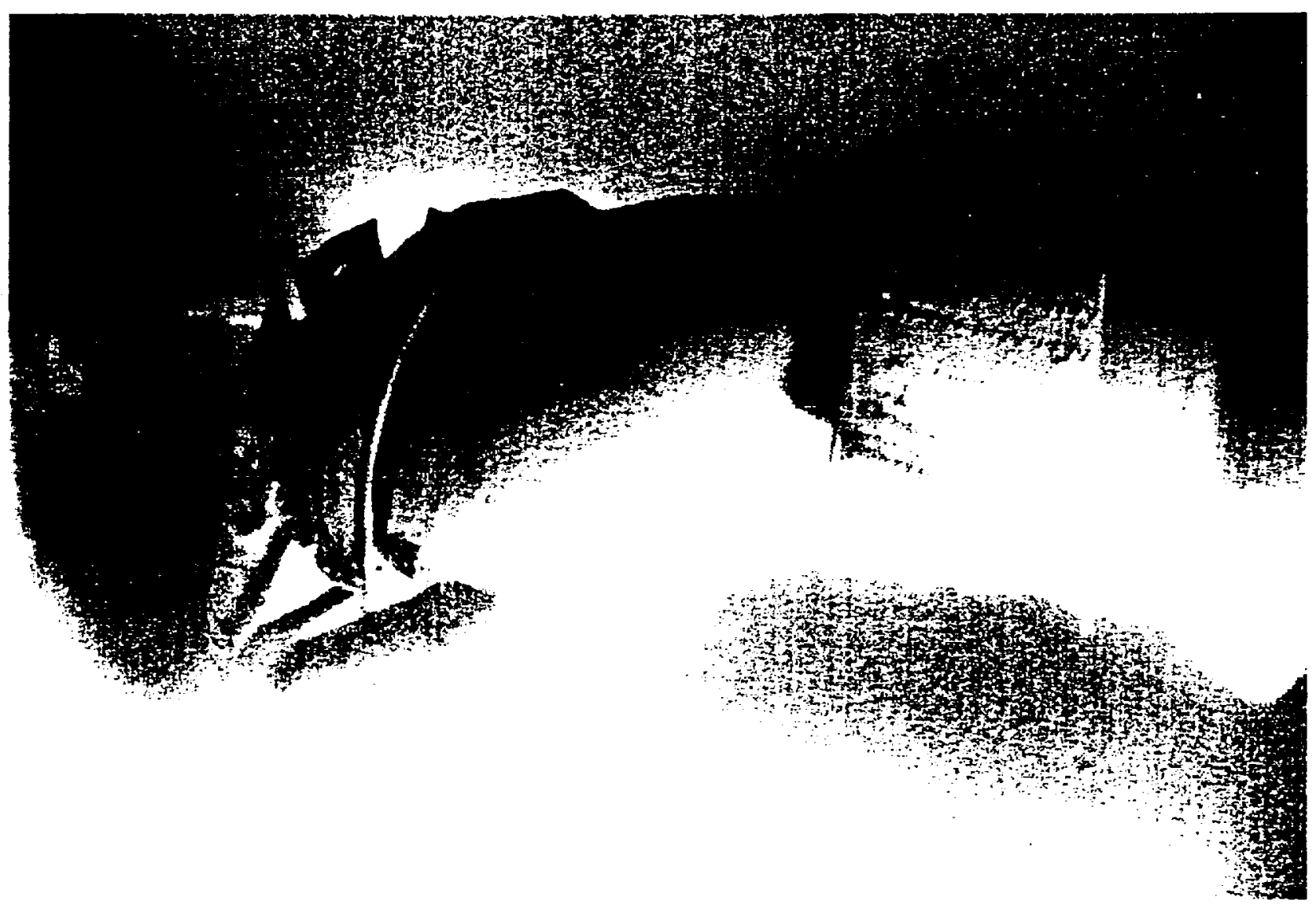

Figure 4. Photo of test glove in the $57.2 \mathrm{kPa}$ glove box without a dorsal assembly. Note the neutral position of the MCP joint. 


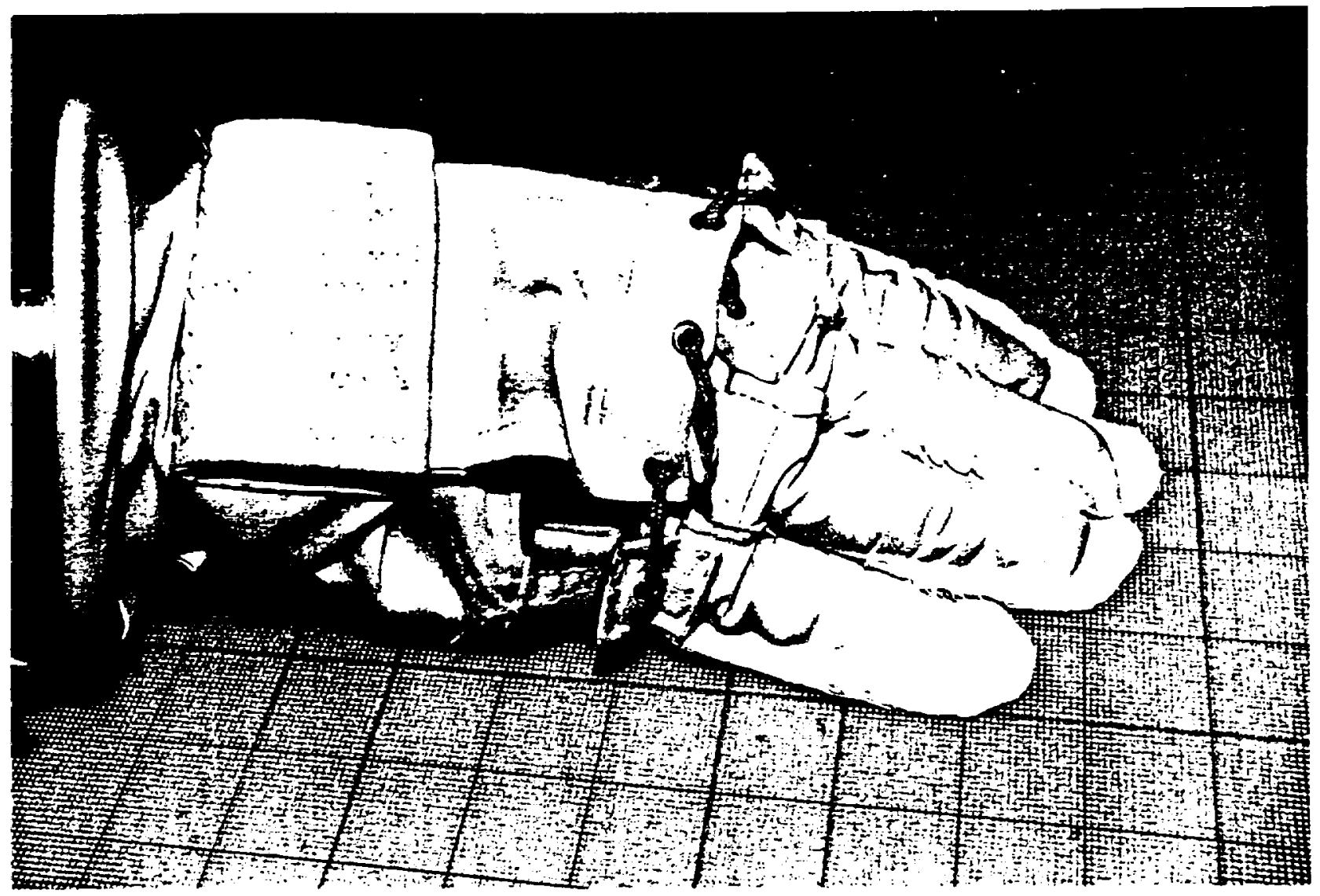

Figure 5. Test glove with the fabric panel dorsal assembly.

$\equiv$

$=$

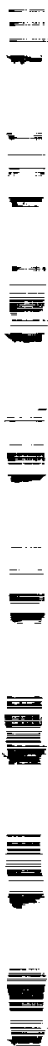
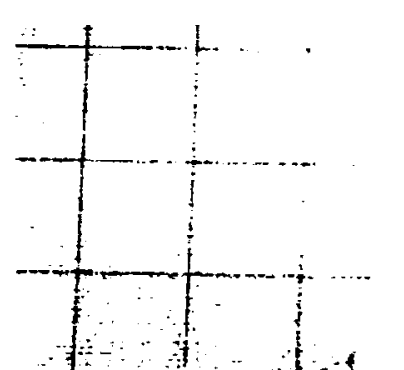

(1)

Figure 5. Test glove with the fabric panel dorsal assembly. 


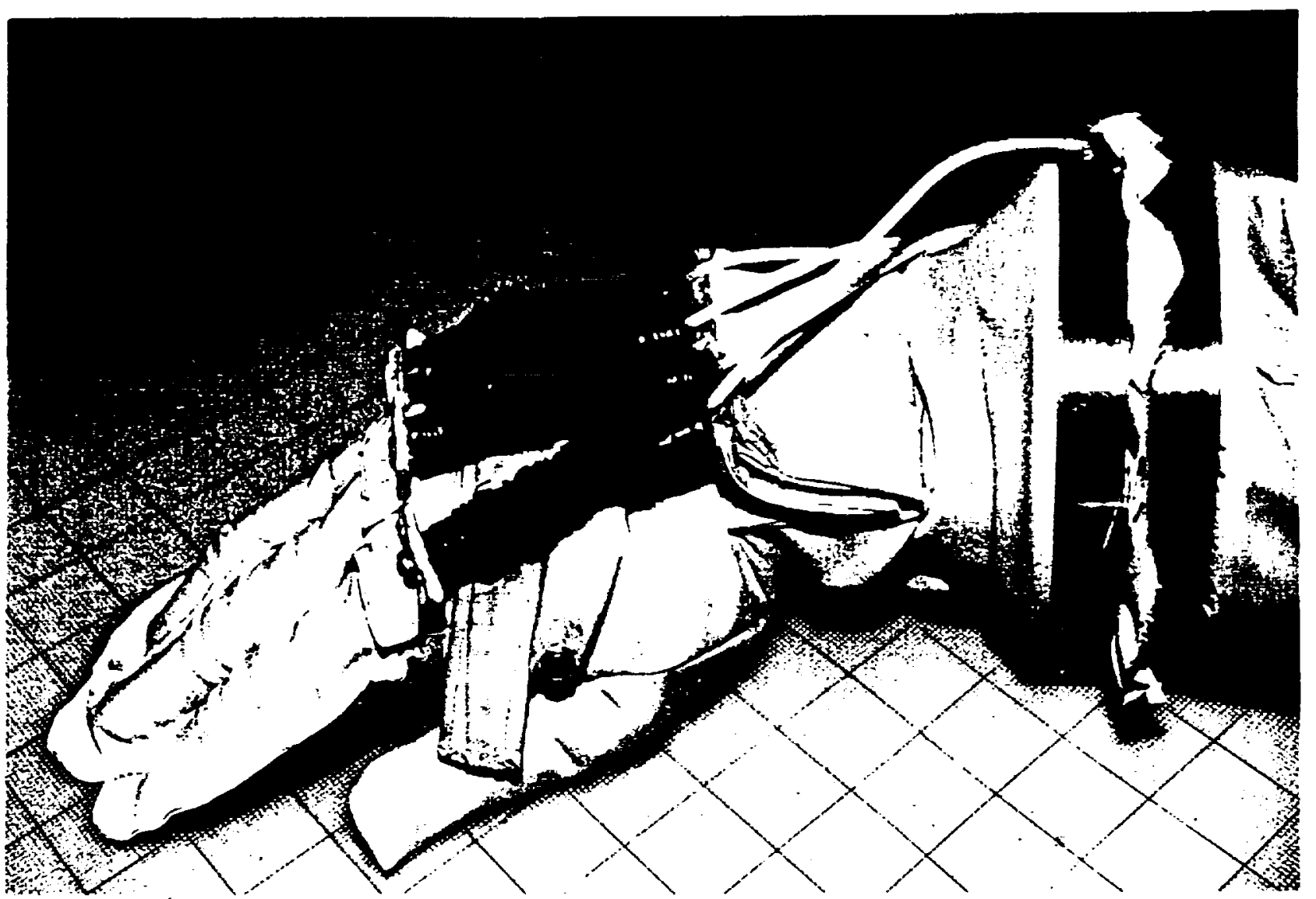

Figure 7. Test glove with pneumatic actuator dorsal assembly.

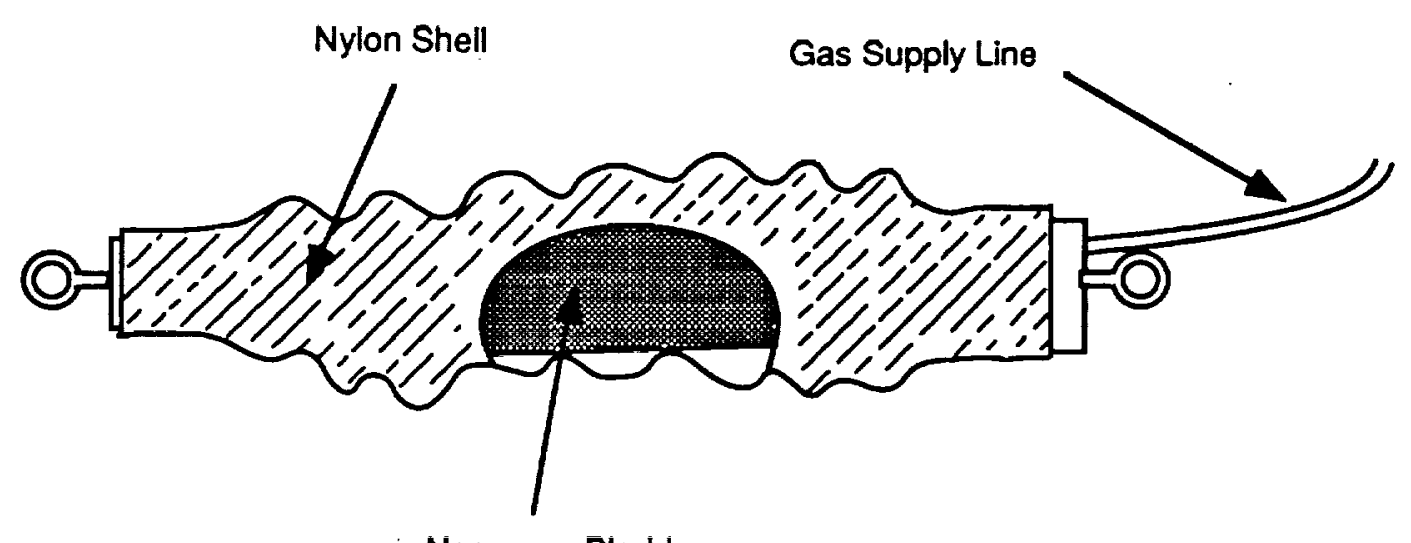

Neoprene Bladder

Figure 8. Sketch of pneumatic actuator. 

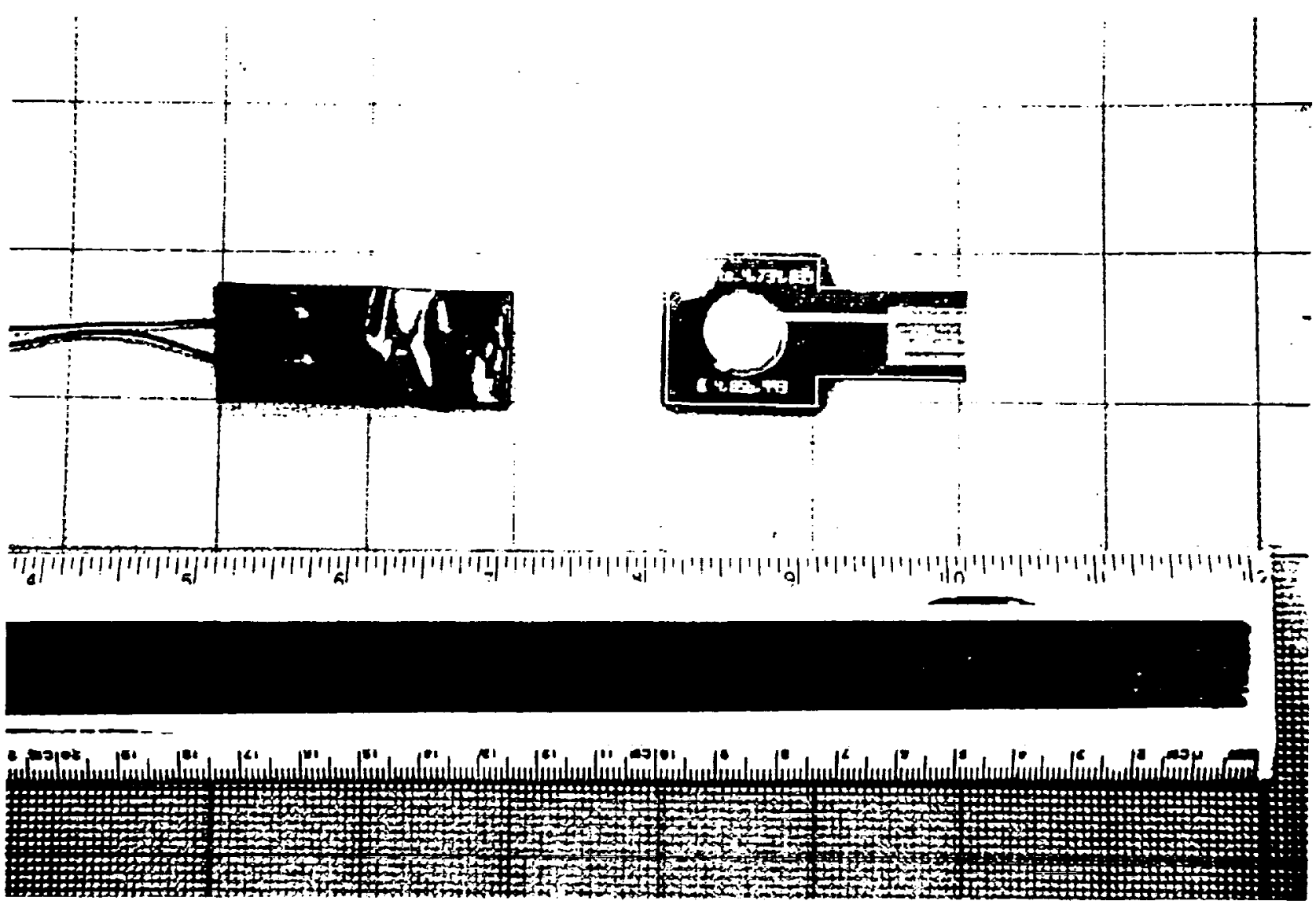

Figure 9. Photo of Tekscan, Inc., pressure sensor. Stock version (right) and after lead attachment (left).

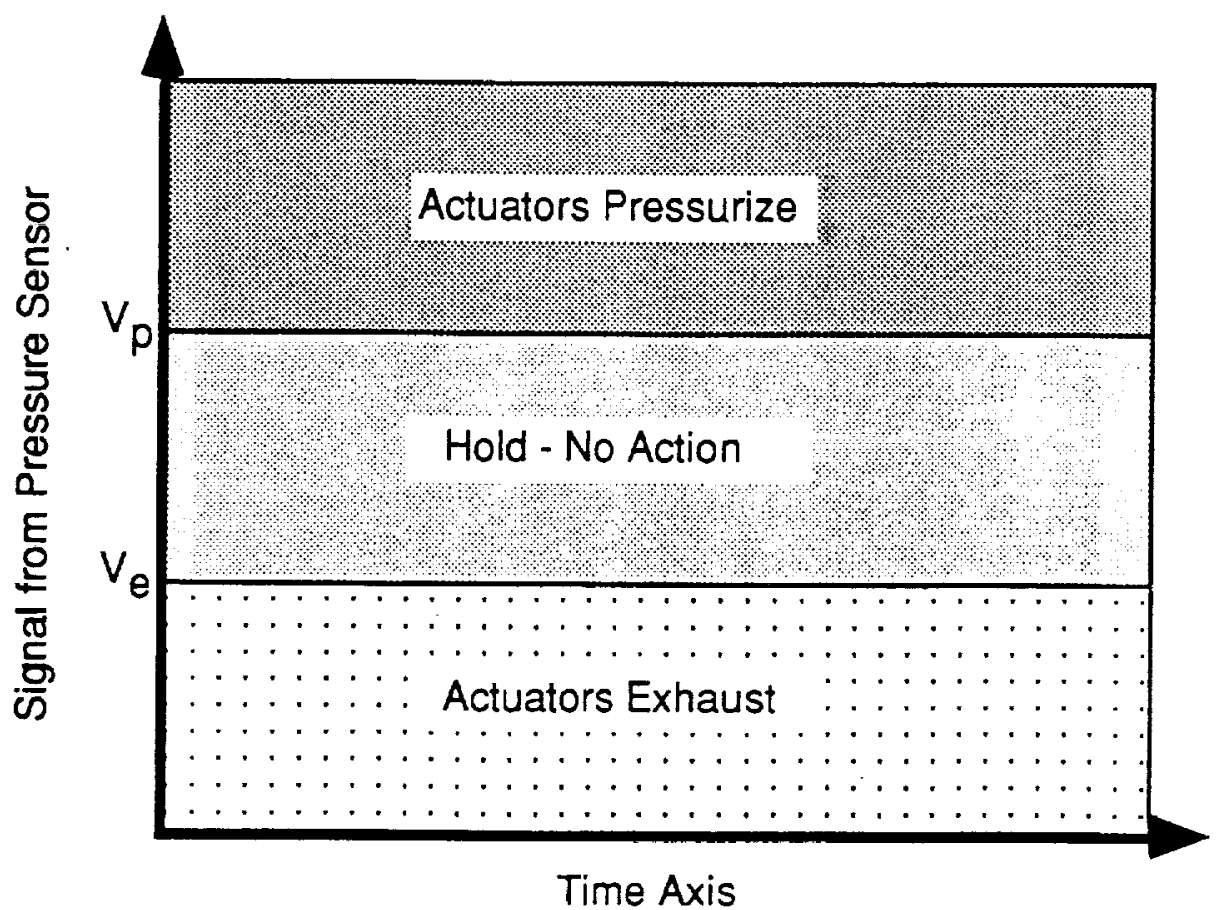

Figure 10. Plot showing control system actions relative to pressure sensor input and threshold settings. 


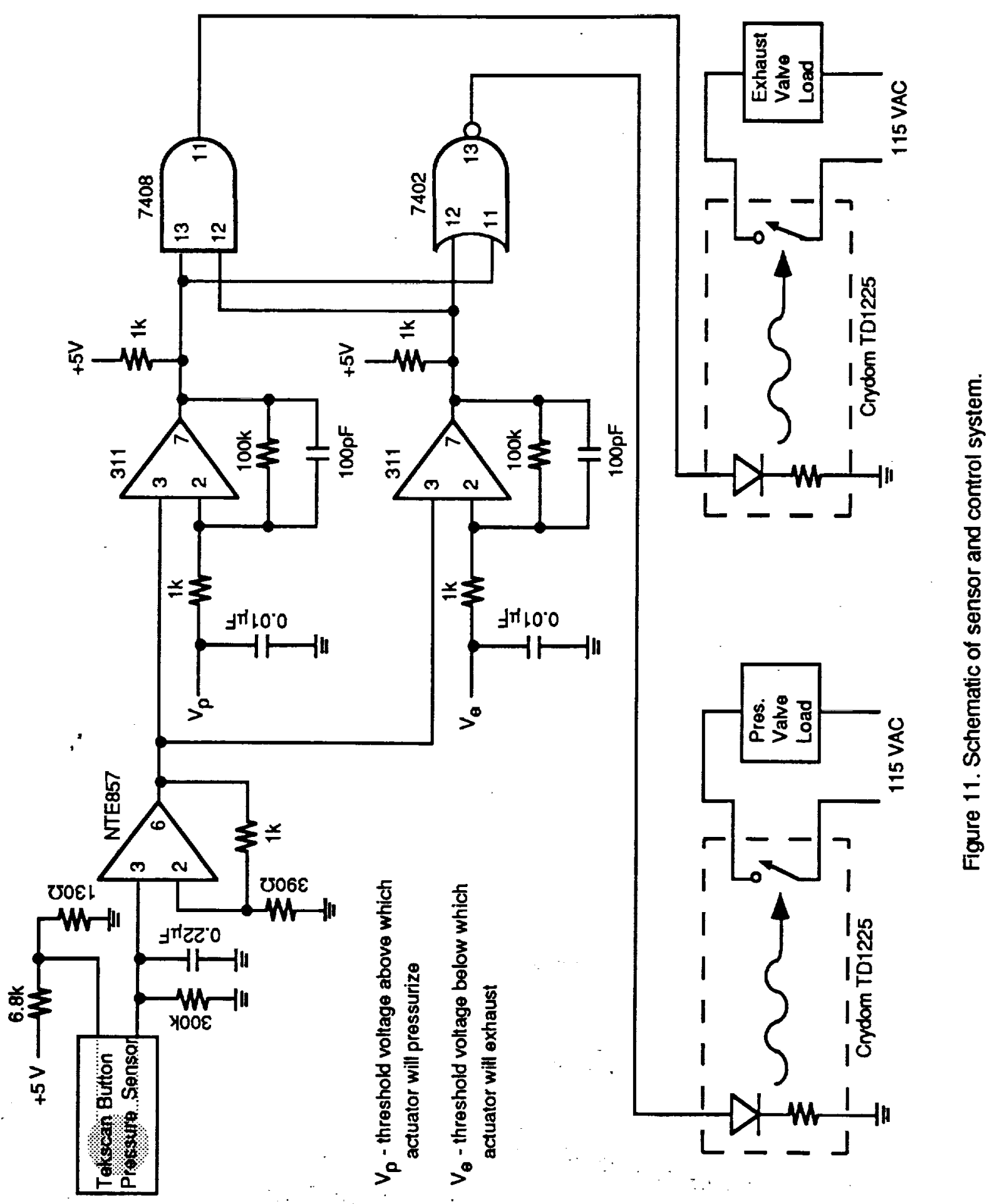


Table 1. Pneumatic Actuator Controller Truth Table.

\begin{tabular}{ccccc}
\hline $\begin{array}{c}\text { Sensor } \\
\text { Output }\end{array}$ & $\begin{array}{c}\text { Voltage Comp. } \\
\text { set at } V_{e}\end{array}$ & $\begin{array}{c}\text { Voltage Comp. } \\
\text { set at } V_{p}\end{array}$ & $\begin{array}{c}\text { Exhaust Valve } \\
\text { (AND) }\end{array}$ & $\begin{array}{c}\text { Pres. Valve } \\
\text { (NOR) }\end{array}$ \\
\hline $\begin{array}{l}<V_{e} \\
>V_{e} \text { and } \\
<V_{p}\end{array}$ & High & High & ON & OFF \\
$>V_{p}$ & Low & High & OFF & OFF \\
\hline
\end{tabular}

\section{EXPERIMENTAL}

Tests of all three glove embodiments consisted of a series of 90 degree flexions of all four fingers. The target frequency for the finger bends was $0.5 \mathrm{~Hz}$. Data was collected at 0.1 second intervals from the Tekscan sensor mounted the base of the palmar face of the middle finger (see Figure 12). The sensor had been previously calibrated so that the voltage output of the conditioning circuit could be translated into finger pressure. A test series consisted of twenty 90 degree bends of the glove MCP joint including all four fingers. Repeatability was insured in the bending task by placing a target object in the glove box in a position where finger contact with the object yielded a 90 degree flexion of the MCP joint.

Tests of the glove with the pneumatic actuator assembly required setting the pressurization and exhaust thresholds prior to the test. For the data presented here $\mathrm{Vp}$ and $\mathrm{Ve}$ were set to $33.4 \mathrm{mV}$ and $20.5 \mathrm{mV}$, respectively. These voltage levels correspond to $89.5 \mathrm{kPa}$ and $47.2 \mathrm{kPa}$ on the sensor calibration curve. Photos of each glove version at neutral inflated position and with fingers flexed at the MCP joint are included as Figures 13 through 18. A plot of typical sensor pressure readings during the 90 degree flexion test is included as Figure 19.

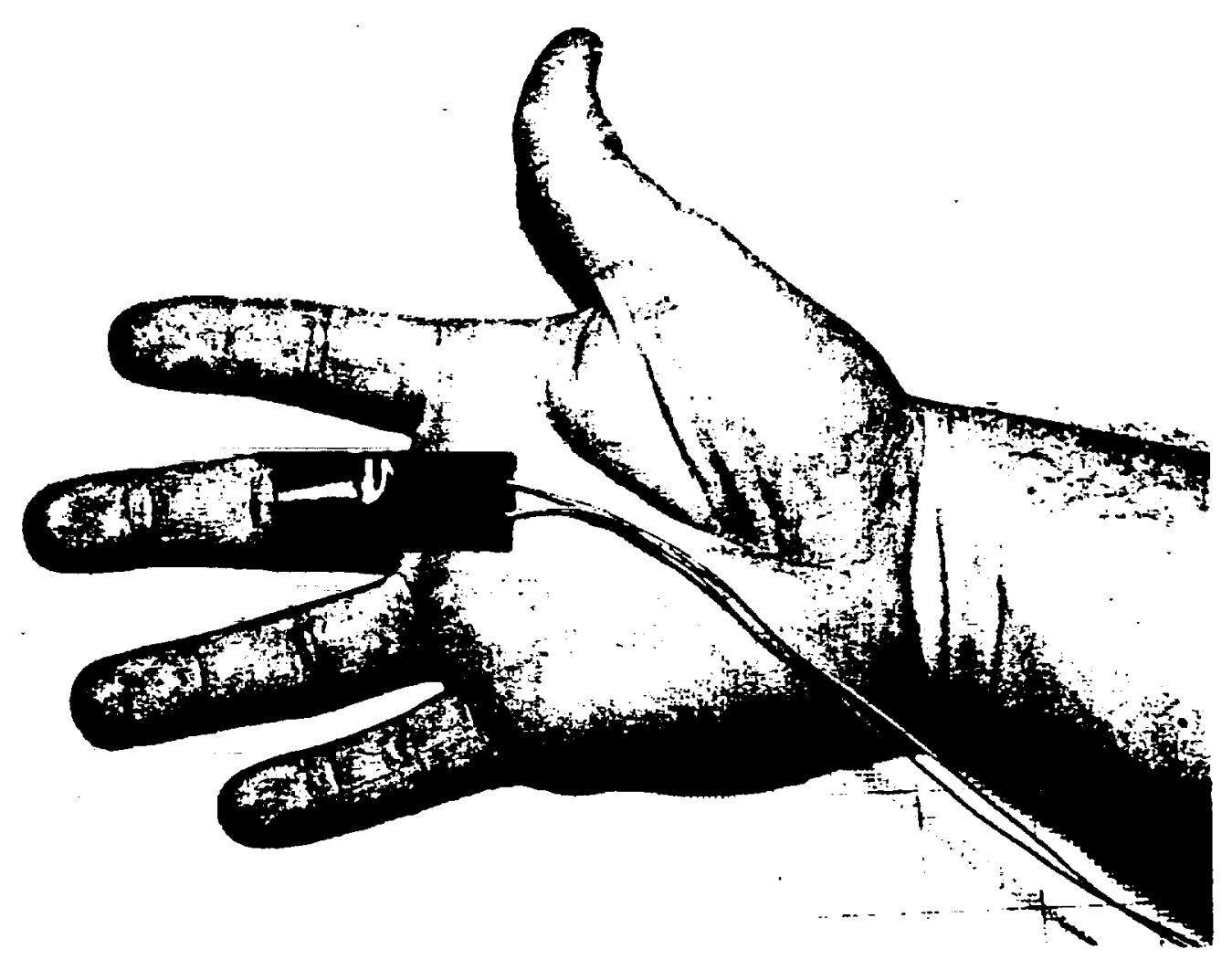

Figure 12. Photo showing sensor application to hand. 


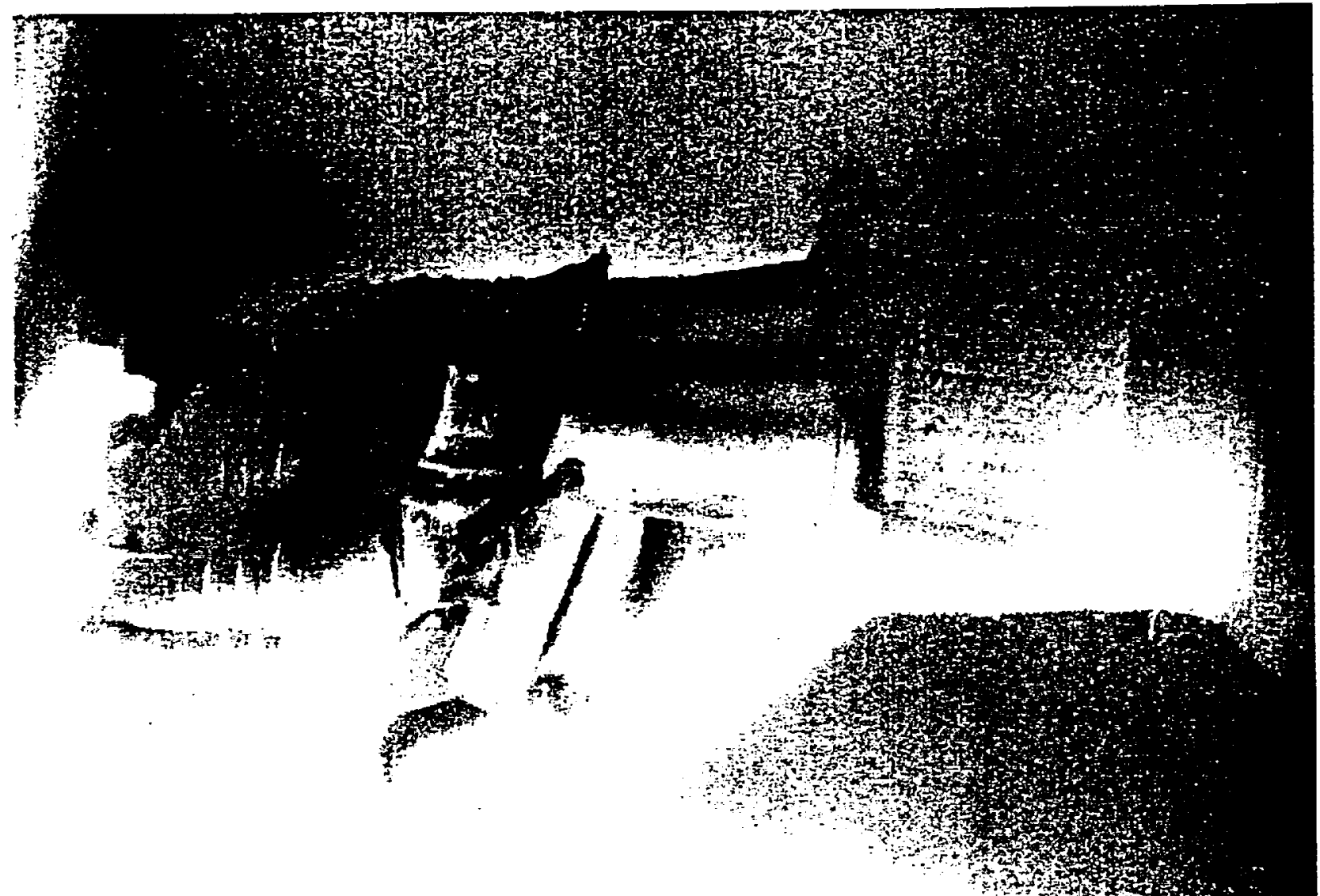

Figure 13. Photo showing the fabric panel version in the pressurized neutral position.

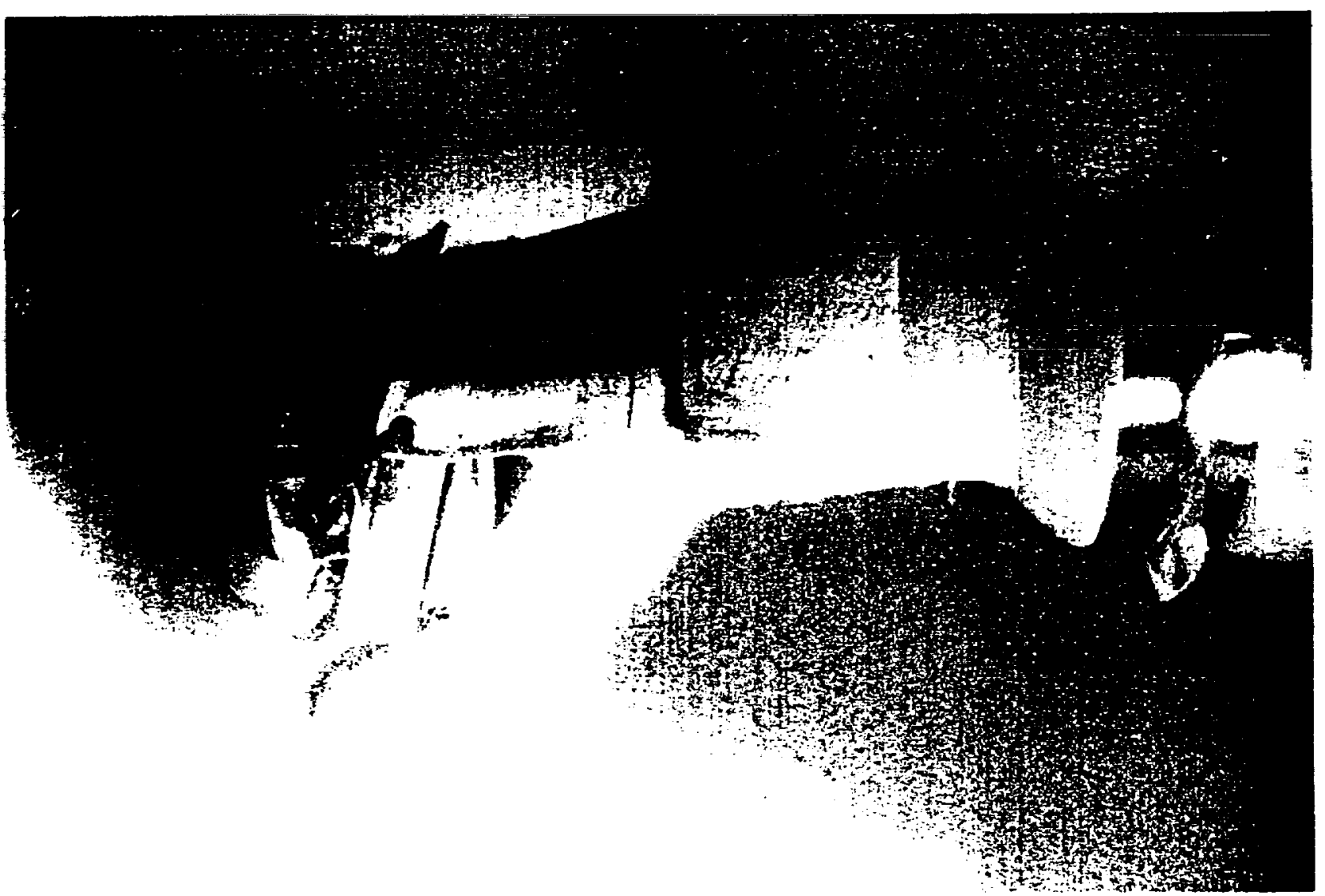

Figure 14. Photo of the fabric panel version in the glove box showing the MCP joint finger flexion. 


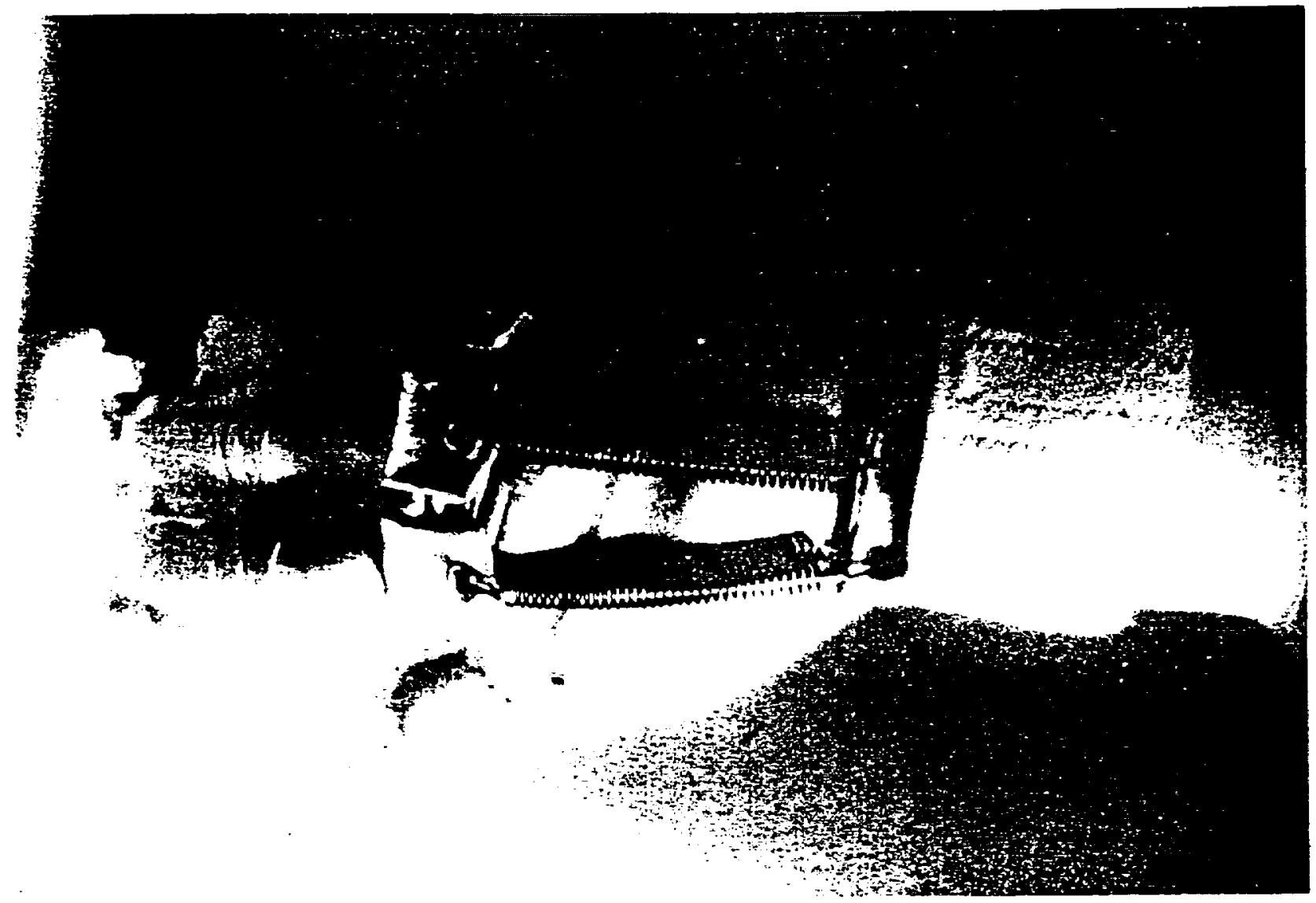

Figure 15. Photo showing the coil spring version in the pressurized neutral position.

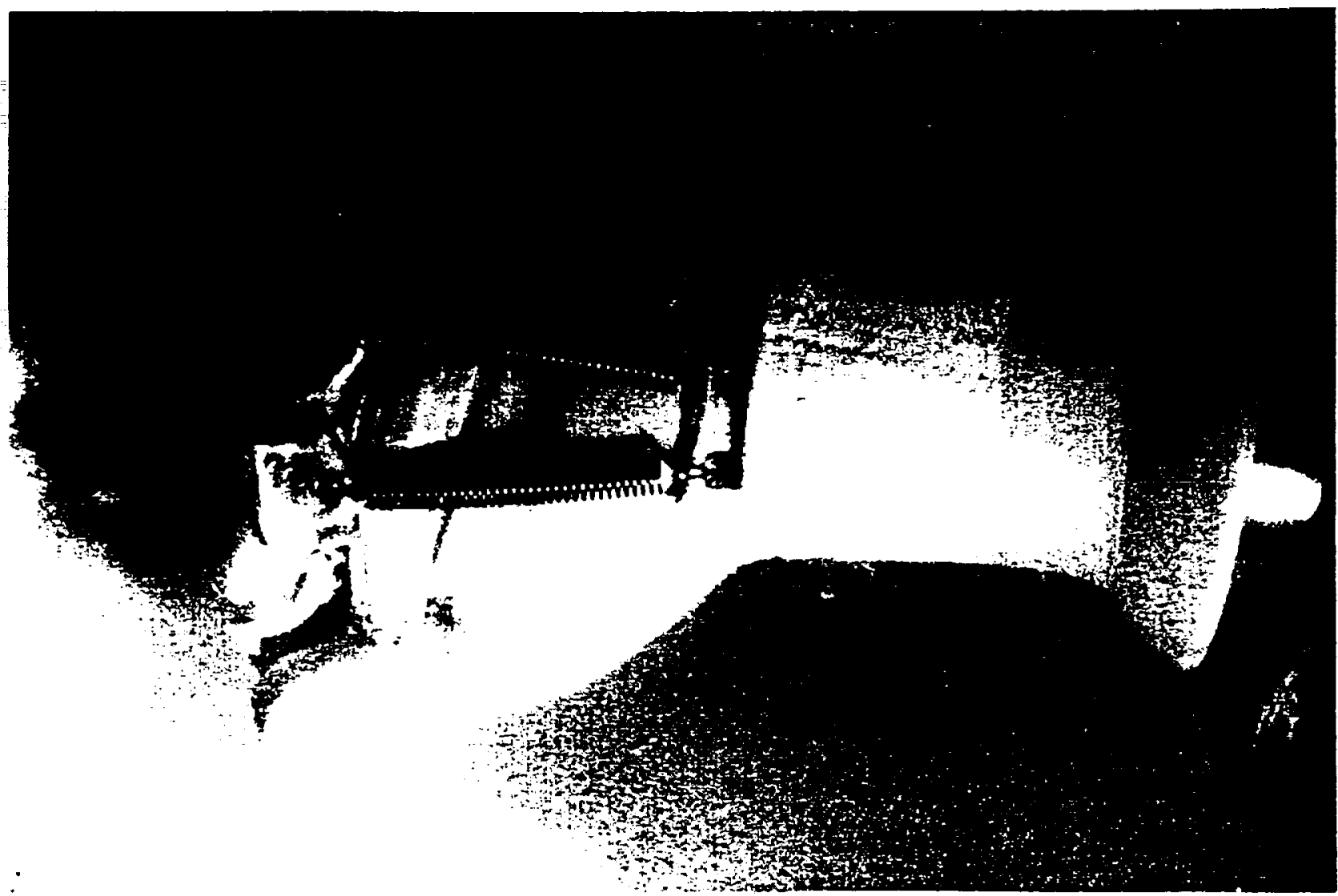

Figure 16. Photo of the coil spring version in the glove box showing MCP joint finger flexion. 


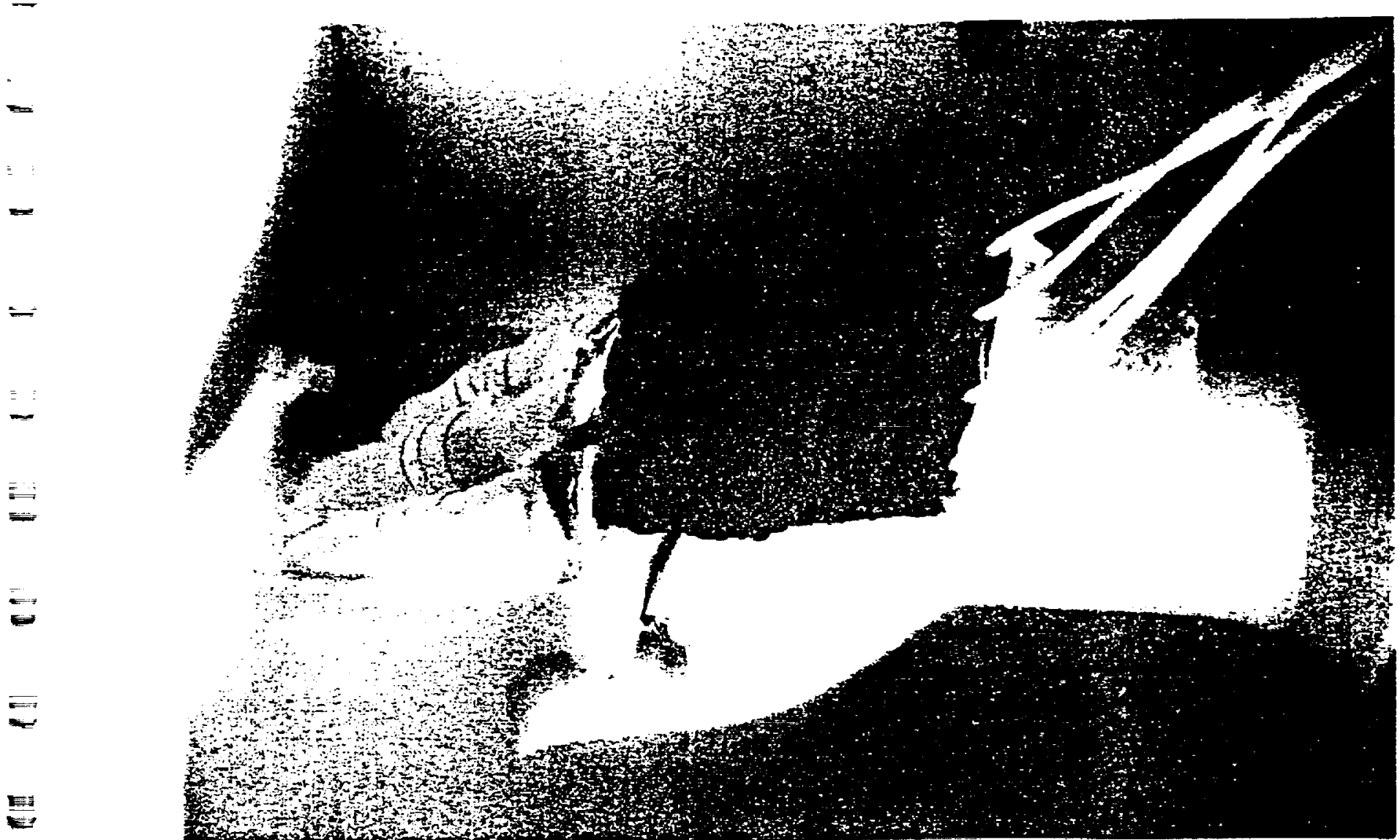

Figure 17. Photo showing the pneumatic actuator version in the pressurized neutral position.

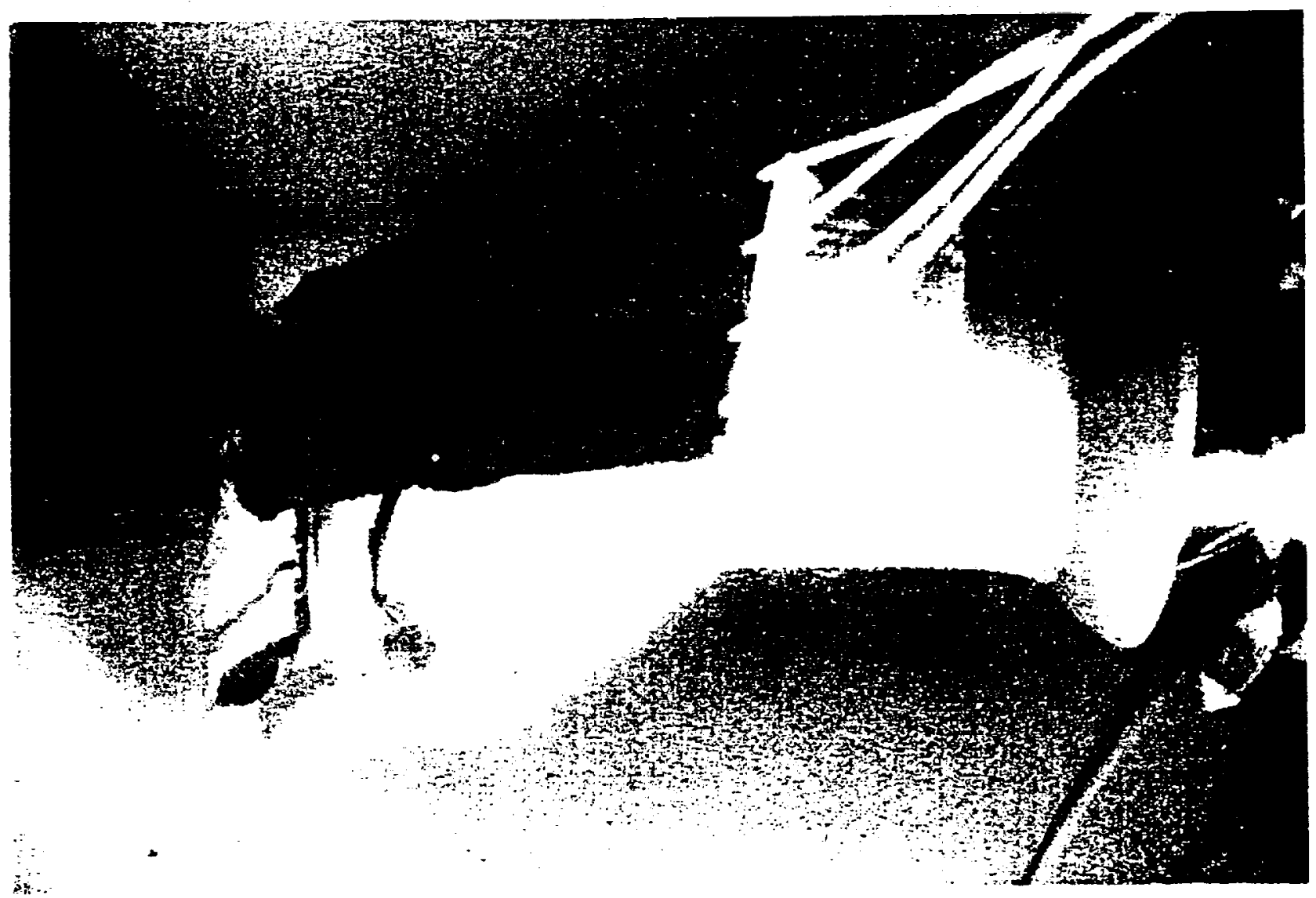

Figure 18. Photo of the pneumatic actuator version in the glove box showing MCP loint finger flexion. 


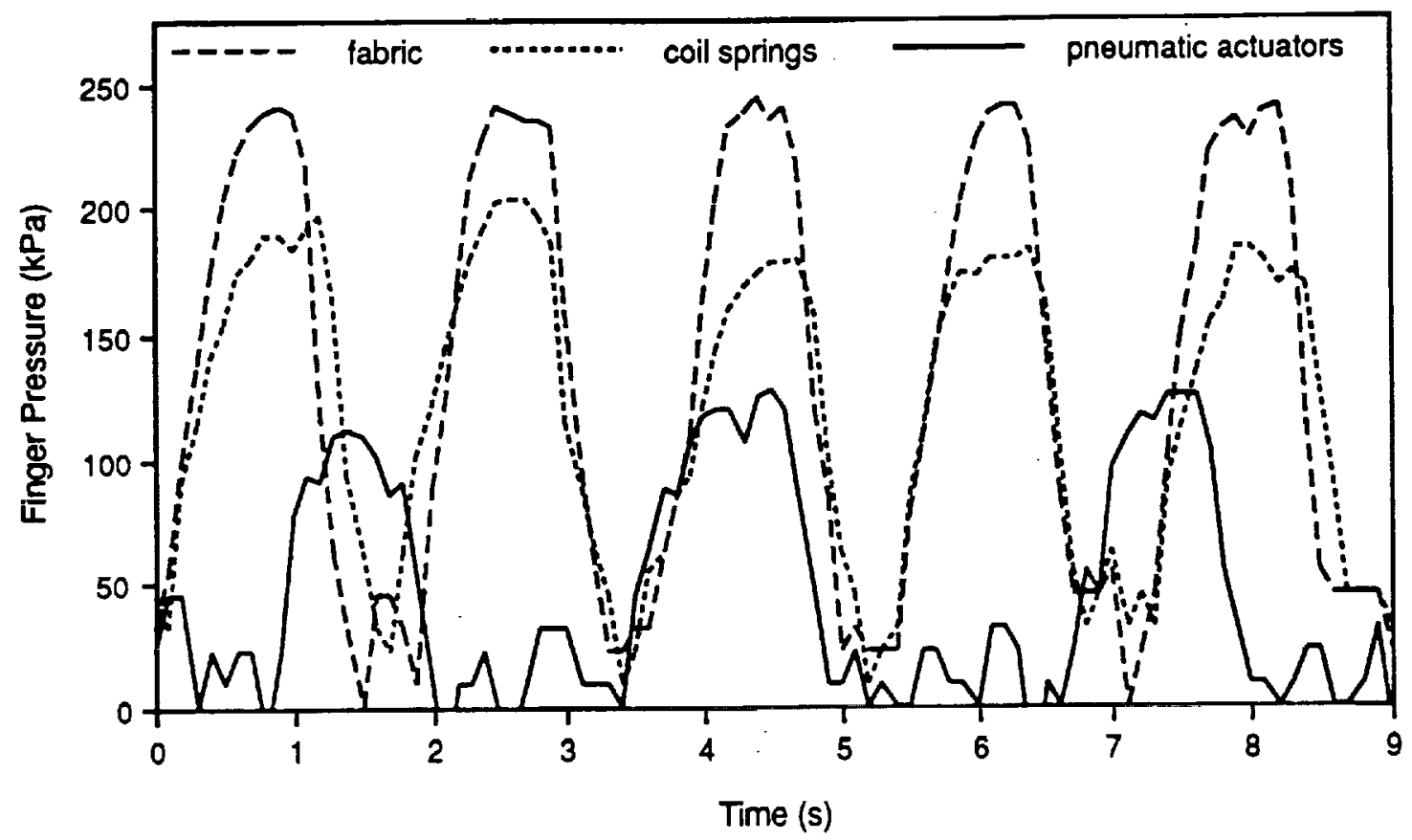

Figure 19. Plot of the pressure between the middle finger and the pressurized test glove during the 90 degree flexion task for the three different dorsal assemblies.

\section{DISCUSSION}

A summary of the peak pressures measured between the middle finger and the test glove for each glove version is included as Table 2. The data presented in the table was generated from the last nine cycles of each test because the data from early in the tests was very erratic. This appears to be caused by a "settling" period that takes place in the glove assembly after each glove box evacuation. The average of the peak pressures measured by the sensor during the flexion tests of the glove with the fabric panel was 237 $\mathrm{kPa}$. By simply replacing the fabric panel with the coil spring assembly the average peak finger pressure dropped $20 \%$ to $190 \mathrm{kPa}$. This assembly also has the advantage of being very low in profile, each spring being no more than $10 \mathrm{~mm}$ in diameter.
An even greater drop in the measured peak finger pressure was found with the pneumatically actuated glove. When the actuators were in use the average peak pressure during bending was found to be $140 \mathrm{kPa}$. This represents a $41 \%$ drop in the resistance of the glove to bending when compared to the fabric panel glove. The increased scatter (S.D. $18.3 \mathrm{kPa}$ ) of the maximum finger pressures in the test of this glove version stems from the flow of compressed nitrogen to and from the glove actuators. This generates additional mechanical noise in the glove structure that is reflected in the pressure sensor readings. The tests of the glove with the pneumatic actuators also showed that this version had a lower maximum 90 degree flexion rate than either the fabric panel or coil spring versions. The data for the actuated glove presented in Figure 19 represents the maximum rate attainable for this version. The time required for

Table 2. Summary of Peak Pressure Data from Finger/Glove Contact Pressure Sensor.

\begin{tabular}{lcr}
\hline Glove Version & Average Maximum Finger Pressure & Standard Deviation \\
\hline Fabric Panel & $237 \mathrm{kPa}$ & $9.3 \mathrm{kPa}$ \\
Coil Spring Assembly & $190 \mathrm{kPa}$ & $9.1 \mathrm{kPa}$ \\
Pneumatic Actuators & $140 \mathrm{kPa}$ & $18.3 \mathrm{kPa}$ \\
\hline
\end{tabular}


exhausting the actuators during the extension phase of each cycle limited the maximum attainable frequency to approximately $0.37 \mathrm{~Hz}$. The pneumatic actuators have the further disadvantage of requiring a pressurized gas supply and gas supply lines for the actuators.

The data obtained in this study qualitatively supports the structural model developed previously. The coil spring assembly, with a lower spring constant than the fabric panel, resulted in less torque required to bend the joint. A further reduction in the spring constant of the dorsal portion of the glove at the MCP joint through the use of active pneumatic components resulted in even a greater improvement in joint flexibility.

Given the validity of the pressurized glove model presented here, there exists an opportunity to lower the joint torque of the glove still further. Examination of Equation 15 indicates that the ideal assembly for the dorsal portion of the glove would be able to carry the load that is present in the glove fabric due to pressurization, yet have an extremely low spring rate. Such components exist and are generally referred to as constant force or negator springs. Future investigations are planned to evaluate the usefulness of these components in high mobility pressurized glove joints. Future investigations must also determine the effects on glove fit and and overall suit performance of allowing the back of the glove to change dimensions to increase glove flexibility.

\section{ACKNOWLEDGEMENTS}

The authors would like to acknowledge the support of the NASA Office of Aeronautics and Exploration Technology and the NASA National Space Grant College and Fellowship Program.

\section{BIBLIOGRAPHY}

Comer, R. L., and Levy, S., "Deflections of an Inflated Circular-Cylindrical Cantilever Beam," AlAA Joumal 1 (July 1963):1652-1655.

Kosmo, J. J., Bassick, J. and Porter, K., "Development of Higher Operating Pressure Extravehicular Space-Suit Assemblies," proceedings of the 18th Intersociety Conference on Environmental Systems in San Francisco, CA, July 11-13, 1988, SAE Paper \#881102.

Main, J. A., Peterson, S. W., and Strauss, A. M., "A Prototype Power Assist EVA Glove," proceedings of the 21st International Conference on Environmental Systems in San Francisco, CA, July 1518, 1991, SAE Paper \#911384.

Spampinato, P., Cadogan, D., McKee, T., and Kosmo, J., "Advanced Technology Application in the Production of Spacesuit Gloves," proceedings of the 20th Intersociety Conference on Environmental Systems in Williamsburg, VA, July 9-12, 1990, SAE Paper \#901322. 